\title{
ERRATUM
}

\section{A high-risk group of pregnant women with elevated levels of conflict-related trauma, intimate partner violence, symptoms of depression and other forms of mental distress in post-conflict Timor-Leste}

SJ Rees, W Tol, M Mohammad, AK Tay, N Tam, N dos Reis, E da Costa, C Soares and DM Silove

Translational Psychiatry (2016) 6, e767; doi:10.1038/tp.2016.33; published online 29 March 2016

Correction to: Translational Psychiatry (2016) 6, e725; doi:10.1038/ tp.2015.212; Published online 2 February 2016

Mohammad Mohsin's name appeared incorrectly in the author list of the published article, and one of his affiliations was omitted. The corrected author list and affiliations appear below:

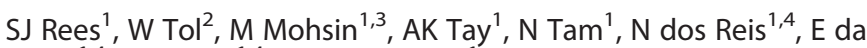
Costa $^{1,4}$, C Soares $^{1,4}$ and DM Silove ${ }^{1}$

${ }^{1}$ Psychiatry Research and Teaching Unit, University of New South Wales and Academic Mental Health Unit, Mental Health Centre,
Liverpool Hospital, Sydney, NSW, Australia; ${ }^{2}$ Bloomberg School of Public Health, Johns Hopkins University, Baltimore, MD, USA; ${ }^{3}$ School of Public Health and Community Medicine, University of New South Wales, Sydney, NSW, Australia; ${ }^{4}$ Child and Maternal Health, Alola Women's Foundation, Dili, Timor-Leste

Additionally, in the abstract, the first reference to post-conflict was incorrect; it should have appeared only as 'low-income, post-conflict (LI-PC).' 